\title{
Microshear Bond Strength of Composite Resin to Enamel Treated With Titanium Tetrafluoride and the Carbon Dioxide Laser (10.6 $\mu \mathrm{m})$ : An In Vitro Study
}

\author{
Narges Panahandeh ${ }^{\oplus}$, Mohadese Azarsina $^{2}{ }^{\circledR}$, Niyayesh Ostad Hossein $^{3}{ }^{\circledR}$, Reza Fekrazad $^{4 *}(\mathbb{D}$ \\ ${ }^{1}$ Associate Professor, Dental Research Center, Research Institute of Dental Sciences, Dental School, Shahid Beheshti \\ University of Medical Sciences. Tehran, Iran \\ ${ }^{2}$ Assistant Professor, Department of Operative Dentistry, Dental School, Shahid Beheshti University of Medical Sciences, \\ Tehran, Iran \\ ${ }^{3}$ Dentist, Tehran, Iran \\ ${ }^{4}$ Professor, Department of Periodontology, Dental Faculty - Laser Research Center in Medical Sciences, AJA University of \\ Medical Sciences, Tehran, Iran
}

\section{*Correspondence to Reza Fekrazad, \\ 1- Department of Periodontology, Dental Faculty - Laser Research \\ Center in Medical Sciences, AJA University of Medical Sciences, Tehran, Iran \\ 2- International Network for Photo Medicine and Photo Dynamic Therapy (INPMPDT), Universal Scientific Education and Research Network (USERN), Tehran, Iran Address: Flat No 12, Mooj building, First Behestan, Pasdaran St, Tehran, Iran \\ Tel: +989123143138 Email: rezafekrazad@gmail.com}

Published online October 3, 2020

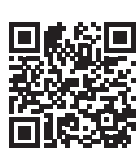

\begin{abstract}
Introduction: The present study aims to assess the microshear bond strength ( $\mu \mathrm{SBS})$ of composite to enamel treated with titanium tetrafluoride $\left(\mathrm{TiF}_{4}\right)$ and $\mathrm{CO}_{2}$ laser irradiation.

Methods: Fifteen human molars were sectioned and their enamel surfaces were abraded. The sections were randomly assigned to 5 groups $(n=15)$ : $(C O)$; control group, (AP); treated with $1.23 \%$ acidulated phosphate fluoride (APF) for 4 minutes, $\left(\mathrm{Ti}_{i}\right) ; 4 \mathrm{TiF}_{4}$ for 1 minute, $(\mathrm{L}+\mathrm{AP}) ; \mathrm{CO}_{2}$ laser irradiation $(10.6 \mu \mathrm{m}$ wavelength, $1 \mathrm{~W}$ peak power, $10 \mathrm{~ms}$ pulse duration, $500 \mathrm{~ms}$ repetition time, $0.2 \mathrm{~mm}$ beam spot size at the tissue level, $2 \mathrm{~cm}$ distance of handpiece tip to tissue surface (DSE, South Cores) followed by $1.23 \% \mathrm{APF}$, and (L+ Ti); $10.6 \mu \mathrm{m} \mathrm{CO}$ laser irradiation followed by $4 \% \mathrm{TiF}_{4}$ for one minute. Using Tygon tubes, Z250 (3M/ESPE) composite was bonded to the surface of the samples. The $\mu \mathrm{SBS}$ of composite to enamel was measured using a microtensile testing machine after 500 thermal cycles. The data were analyzed by one-way ANOVA and the Tukey HSD test $(P<0.05)$.

Results: The mean $\mu$ SBS was 20.66, 20.21, 13.44, 23.01, and $10.16 \mathrm{MPa}$ in CO, AP, Ti, L+AP, and $\mathrm{L}+\mathrm{Ti}$ groups respectively. Significant differences were observed between $\mathrm{CO}$ and $\mathrm{Ti}(P=0.026)$ and also $\mathrm{CO}$ and $\mathrm{L}+\mathrm{Ti}(P<0.0001)$.

Conclusion: The application of $\mathrm{TiF}_{4}$ per se and after $\mathrm{CO}_{2}$ laser irradiation on enamel decreased the $\mu \mathrm{SBS}$ of composite to enamel; on the other hand, APF alone and after laser irradiation did not have any adverse effect on the $\mu$ SBS of composite to enamel.

Keywords: Acidulated phosphate fluoride; $\mathrm{CO}_{2}$ lasers; Composite resins; Strength; Titanium tetrafluoride.
\end{abstract}

\section{Introduction}

Tooth decay is an infectious disease during which dental hard tissue is demineralized by the action of acids produced by the metabolism of cariogenic bacteria. If this process is stopped early enough, remineralization may occur. Several methods have been recommended for caries prevention such as fissure sealant therapy, the application of fluoride compounds and antimicrobial agents and laser irradiation. ${ }^{1}$

Fluoride plays an important role in caries prevention. Fluoride is available in the forms of gel, varnish and solution for topical application. The mechanism of the action of fluoride is via the enhancement of remineralization and prevention of tooth demineralization. ${ }^{2}$ Different compositions of fluoride such as sodium fluoride $(\mathrm{NaF})$, stannous fluoride ( $\mathrm{SnF} 2)$, amine fluoride $(\mathrm{AmF})$ and acidulated phosphate fluoride (APF) are used for caries prevention. ${ }^{3}$ The APF is an acidic compound which not only enhances the reaction of fluoride with enamel hydroxyapatite crystals by superficial demineralization, but also increases the concentration of phosphate and fluoride ions at the reaction site and prevents the development of caries. ${ }^{4}$ A new fluoride compound, titanium tetrafluoride $\left(\mathrm{TiF}_{4}\right)$, has recently been introduced to the market and is non-toxic with no reported complications so far. The optimal cariostatic

Please cite this article as follows: Panahandeh N, Azarsina M, Ostad Hossein N, Fekrazad R. Microshear bond strength of composite resin to enamel treated with titanium tetrafluoride and the carbon dioxide laser $(10.6 \mu \mathrm{m})$ : an in vitro study. J Lasers Med Sci. 2020;11(4):486490. doi:10.34172/jlms.2020.76. 
efficacy of $\mathrm{TiF}_{4}$ is attributed to the replacement of calcium in the composition of hydroxyapatite and the formation of titanium phosphate complexes. ${ }^{3}$

Titanium reacts with oxygen in water or hydroxyapatite and forms $\mathrm{TiO}_{2}$, which confers acid resistance and enhances fluoride uptake by the enamel. Titanium dioxide forms a transparent glaze-like, non-globular layer on the tooth surface. ${ }^{3}$ Evidence shows that this transparent layer can increase the mineral content of enamel ${ }^{5}$ and serve as a fluoride ion reservoir. Greater fluoride uptake following the application of $\mathrm{TiF}_{4}$ is due to the bond of fluoride and metal ions to hydroxyapatite crystals. Due to the greater absorption of this particular fluoride compound compared to other forms, it has higher efficacy. Also, given that the smear layer is eliminated due to the highly acidic nature of $\mathrm{TiF}_{4}{ }^{3}$ it can penetrate into dentin and form a granular layer on the surface of dentin, decreasing dentin hypersensitivity. ${ }^{6}$ Moreover, $\mathrm{TiF}_{4}$ has antimicrobial properties and prevents bacterial colonization. ${ }^{6}$

$\mathrm{TiF}_{4}$ has a low $\mathrm{pH}$ and high affinity for a bond to oxygen atoms in a phosphate group; it forms a strong bond to the enamel surface as such. ${ }^{7}$ After the application of $\mathrm{TiF}_{4}$, titanium compounds containing - Ti-O-Ti-Ochains are formed on the tooth surface ${ }^{8}$ and a strong complex is formed between the titanium compounds and hydroxyapatite. This theory regarding the bond of titanium reaction products to enamel is highly likely; however, it was maintained that the validity and nature of this bond must be further assessed.

Lasers have also been suggested for caries prevention. ${ }^{9}$ The wavelength of the $\mathrm{CO}_{2}$ laser matches the absorbance spectrum of hydroxyl and phosphate groups in enamel hydroxyapatite crystals $(9-11 \mu \mathrm{m})$. Thus, it is well absorbed only by the tooth surface without any adverse effect on pulp and can prevent dental caries. It enhances the efficacy of fluoride and increases fluoride uptake by the enamel. It prevents enamel demineralization and facilitates the conversion of hydroxyapatite to fluorapatite. ${ }^{10,11}$ It also improves the cariostatic efficacy of fluoride-containing compounds such as NAF, APF and AmF. However, a few studies have been conducted regarding the effects of the combination of the $\mathrm{CO}_{2}$ laser and $\mathrm{TiF}_{4}$.

Rodriguez et al in 2004 evaluated the efficacy of the $\mathrm{CO}_{2}$ laser for caries prevention in enamel and dentin and assessed its effect in combination with fluoride. ${ }^{12}$ They showed that $\mathrm{CO}_{2}$ laser irradiation in different wavelengths modified the hydroxyapatite crystals and changed their reaction to acid attack.

In addition, $\mathrm{CO}_{2}$ laser irradiation with fluoride had greater efficacy in the prevention of caries-like lesions compared to their use alone. ${ }^{13}$ In contrast, some studies reported that there was no significant difference between the outcomes of the irradiation of lasers before or after fluoride therapy. ${ }^{14}$ Topical applications of fluoride could a) promote enamel resistance to caries due to the less solubility of enamel in acidic conditions and b) prevent enamel decalcification. ${ }^{15}$ The application of fluoride results in the formation of fluorapatite deposits and may negatively affect the bond strength between enamel and composite resin material. ${ }^{16-18}$

This in vitro study aimed to evaluate the micro-shear bond strength ( $\mu \mathrm{SBS}$ ) of composite resin material to enamel treated with $\mathrm{TiF}_{4}$ and the $\mathrm{CO}_{2}$ laser. The null hypothesis was that the $\mu \mathrm{SBS}$ of composite resin material to enamel would not be significantly different after various surface treatments for caries prevention.

\section{Materials and Methods}

This in vitro experimental study was conducted on 15 extracted human sound molars which were stored in $1 \%$ saline until the experiment. The sample size was calculated to be 15 in each group considering the expected difference of mean $\mu$ SBS among the four groups to be 8 , 10,15 and $20 \mathrm{MPa}$ and standard deviation of 9 according to a previous study. ${ }^{19}$ The effect size of 0.52 , the study power of $90 \%$, and $\alpha=0.05$ in conjunction with Power Analysis and Sample Size software version 14 (PASS) were used to calculate the sample size (Total $=75$ ).

The teeth were free from caries and surface defects such as cracks. After disinfection using 1\% thymol solution, the teeth were sectioned into five slices by a cutting machine (Mecatome T201A, Persi, Germany) and each slice was mounted in red dental wax. The convex enamel surface was ground by 600-grit silicon carbide abrasive papers under water coolant to achieve a smooth and flat enamel surface for bonding to the composite and bond strength testing. Vinyl tape with a hole in it ( $2 \mathrm{~mm}$ diameter) was fixed on the abraded enamel surface for the purpose of standardization. Each slice was randomly allocated to one group as follows:

CO: No treatment (control group), AP: 1.23\% APF gel was applied over the surface of samples for four minutes and was rinsed and dried, $\mathrm{Ti}: 4 \% \mathrm{TiF}_{4}$ was applied over the surface of samples for one minute ${ }^{20}$ and was rinsed and dried, and L+AP: the CO2 Laser (DSE, South Korea) (Figure 1A) was irradiated on the surface of samples followed by the application of $1.23 \%$ APF gel for 4 minutes.

The $\mathrm{TiF}_{4}$ gel with $\mathrm{pH}=1.2$ was prepared by the dissolution of $4 \mathrm{~g}$ of $\mathrm{TiF}_{4}$ powder (Aldrich Chemical Company, Milwaukee, WI, USA) in $100 \mathrm{~mL}$ deionized water and the addition of carboxymethyl cellulose immediately before the application.

The samples were then rinsed and dried. Laser parameters (Figure 1B) included $10.6 \mu \mathrm{m}$ wavelength, pulse mode, $1 \mathrm{~W}$ power peak, $0.2 \mathrm{~W}$ average power, $64 \mathrm{~W} /$ $\mathrm{cm}^{2}$ power density, $10 \mathrm{~ms}$ pulse width, $1 \mathrm{~Hz}$ frequency, 500 ms interval time, 10 seconds exposure time in a scanning movement, $640 \mathrm{~W} / \mathrm{cm}^{2}$ energy density, $0.2 \mathrm{~mm}$ spot size at the tissue level, and $2 \mathrm{~cm}$ distance of handpiece tip from the surface. The irradiation was in a pulsed mode. The L+Ti: CO2 laser was irradiated on the surface of samples as in the L+AP group followed by the application of $4 \%$ 

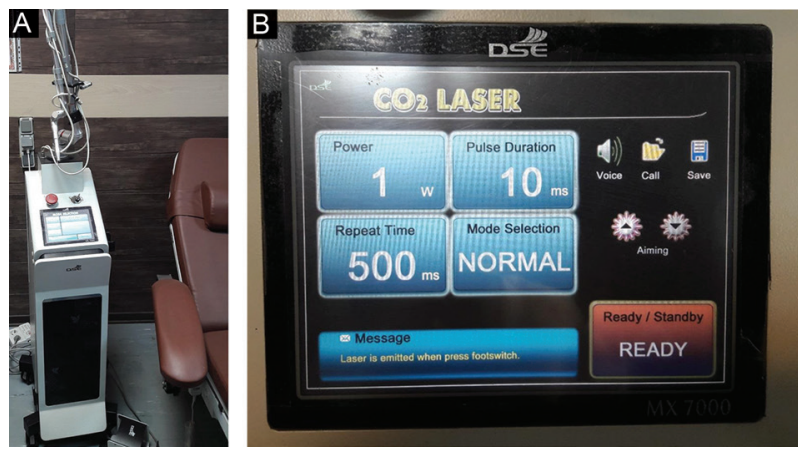

Figure 1. (A) Laser Device. (B) Laser Parameters.

$\mathrm{TiF}_{4}$ gel for one minute. The samples were then rinsed and dried. Laser irradiation was carried out by a skilled operator who was blind to the study design and the laser was irradiated for 10 seconds in a scanning movement. All the materials were used according to the manufacturers' instructions.

The teeth were then stored in artificial saliva until the bonding procedure. The surface of samples was etched with $37 \%$ phosphoric acid for 15 seconds (3M ESPE, St. Paul, MN, USA) according to the manufacturer's instructions, rinsed and dried. Two-step etch and rinse adhesive, single bond, (3M ESPE, St., Paul, MN, USA) was then applied and light-cured with a LED light-curing unit (Demetron LC, Kerr, USA) for 20 seconds (600 $\left.\mathrm{mW} / \mathrm{cm}^{2}\right)$. A Tygon tube $(0.7 \times 2 \mathrm{~mm})$ was placed on the surface of samples and filled with the Z250 micro-hybrid composite (3M ESPE, St. Paul, MN, USA). The samples were light-cured for 40 seconds, stored for 24 hours and subjected to 500 thermal cycles between $5-55^{\circ} \mathrm{C}$ prior to $\mu$ SBS assessment. Specimens were tested in a microtensile testing machine (Bisco, Livonia, MI, USA) with a crosshead speed of $0.5 \mathrm{~mm} / \mathrm{min} .^{21}$ The load at failure was recorded in Newton $(\mathrm{N})$ and divided by the surface area in $\mathrm{mm}^{2}$ to yield the $\mu \mathrm{SBS}$ value in $\mathrm{MPa}$.

\section{Statistical Analysis}

The data were analyzed using SPSS version 22. The Kolmogorov-Smirnov test was applied to assess the normal distribution. One-way ANOVA was applied to detect the differences in $\mu$ SBS. The Tukey HSD test was used for pairwise comparisons and $P<0.05$ was considered statistically significant.

\section{Results}

The mean, standard deviation (SD), maximum and minimum $\mu$ SBS values of the composite to enamel in different groups are presented in Table 1 . The mean \pm SD of $\mu \mathrm{SBS}$ was $20.66 \pm 7.94,20.21 \pm 3.49,13.44 \pm 5.29$, $23.01 \pm 9.38$ and $10.16 \pm 4.43 \mathrm{MPa}$ in $\mathrm{CO}, \mathrm{AP}, \mathrm{Ti}, \mathrm{L}+\mathrm{AP}$ and L+Ti groups respectively. The Kolmogorov-Smirnov test revealed that the data were normally distributed. According to one-way ANOVA, significant differences were noted among the five groups in $\mu$ SBS $(P<0.05)$. Thus, the Tukey HSD test was applied for pairwise comparison of the groups. It revealed that the groups treated with APF either with laser irradiation or alone showed no significant differences with the control group. Significant differences were observed between the groups treated with $\mathrm{TiF}_{4}$ and all other groups whether used in conjunction with laser irradiation or not $(P<0.05)$. In fact, a significant reduction was detected when $\mathrm{TiF}_{4}$ was applied. Therefore, the null hypothesis was rejected. The results of pairwise comparisons are shown in Table 2.

\section{Discussion}

Mechanical retention plays an important role in the adhesion of the composite to prepared enamel surfaces. The penetration of resin tags into microscopic pores and their mechanical interlocking plays an important role in the formation of a strong bond. This study was conducted to investigate the combined effect of $\mathrm{TiF}_{4}$ and $\mathrm{CO}_{2}$ laser application on the bond strength of composite resin to enamel.

The results of the present study showed that the application of $\mathrm{TiF}_{4}$ either with or without $\mathrm{CO}_{2}$ laser irradiation resulted in significantly lower bond strength. Reduction in $\mu$ SBS following the application of fluoridated agents was attributed to the deposition of crystals, ${ }^{18,22}$ which are acid-resistant and may physically or chemically prevent complete penetration of adhesive resin. Sheykholeslam et al showed complete degradation of the resin bond to bovine enamel following the application of $\mathrm{TiF}_{4}$ for five minutes. ${ }^{23}$ It was proposed that acid-resistant globular deposits are the main cause of the reduction in

Table 1. The Mean (MPa), Standard Deviation, Maximum and Minimum Shear Bond Strength Values of the Composite to Enamel of the Study Groups

\begin{tabular}{lcccc}
\hline Group Name & Mean & SD & Minimum & Maximum \\
\hline $\mathrm{CO}$ & 20.66 & 7.94 & 9.90 & 36.20 \\
$\mathrm{AP}$ & 20.21 & 3.49 & 14.20 & 27.30 \\
$\mathrm{Ti}$ & 13.44 & 5.29 & 7.50 & 27.70 \\
$\mathrm{~L}+\mathrm{AP}$ & 23.01 & 9.38 & 9.10 & 38.80 \\
$\mathrm{~L}+\mathrm{Ti}$ & 10.16 & 4.43 & 3.60 & 18.50 \\
\hline
\end{tabular}

Table 2. Pairwise Comparison of the Groups Using the Tukey HSD Test

\begin{tabular}{lcc}
\hline Group 1 & Group 2 & P Value \\
\hline \multirow{4}{*}{$\mathrm{CO}$} & $\mathrm{L}+\mathrm{AP}$ & 0.859 \\
& $\mathrm{AP}$ & 1.00 \\
& $\mathrm{Ti}$ & $\mathbf{0 . 0 2 6}$ \\
& $\mathrm{L}+\mathrm{Ti}$ & $\mathbf{0 . 0 0 0}$ \\
$\mathrm{L}+\mathrm{Ti}$ & $\mathrm{Ti}$ & 0.641 \\
& $\mathrm{~L}+\mathrm{AP}$ & $\mathbf{0 . 0 0 0}$ \\
$\mathrm{L}+\mathrm{AP}$ & $\mathrm{AP}$ & $\mathbf{0 . 0 0 1}$ \\
$\mathrm{AP}$ & $\mathrm{Ti}$ & $\mathbf{0 . 0 0 1}$ \\
& $\mathrm{AP}$ & 0.763 \\
\hline
\end{tabular}


bond strength since they inhibit resin tag formation and decrease the wettability of enamel.

Evidence shows the fast formation of compounds by the reaction of $\mathrm{TiF}_{4}$ or its derivatives with phosphate or organic contents of dentin. ${ }^{24}$ A glaze-like layer is formed, which is referred to as the organometallic complex. This complex forms a strong titanium-rich coating on the tooth surface, which is stable against acidic and alkaline wear. $^{24,25}$ The presence of a strong coating with $0.1 \mu$ thickness has been reported on surfaces treated with $\mathrm{TiF}_{4}{ }^{26}$ Another study reported the presence of a glazelike layer on the occlusal surface of posterior teeth for up to one year following the application of $\mathrm{TiF}_{4}{ }^{27}$

As it was mentioned earlier, a further decrease in bond strength was observed when $\mathrm{TiF}_{4}$ was used in conjunction with the $\mathrm{CO}_{2}$ laser. It was maintained that $\mathrm{TiF}_{4}$ requires organic groups to form organometallic complexes on the tooth surface. ${ }^{16,17}$ After laser irradiation, the organic content of the enamel surface decreases. Apatite crystals fuse and form a more mineralized structure. It appears that $\mathrm{TiF}_{4}$ can no longer affect the surface, and the lasermodified smooth surface cannot be well-etched to form micromechanical bonds with adhesive resin.

The glaze-like layer on the surface (which prevents adequate tooth surface preparation by phosphoric acid) can form chemical bonds with the adhesive depending on the acidity and composition of the adhesive used. This explains the further reduction in bond strength in the laser plus $\mathrm{TiF}_{4}$ group compared to $\mathrm{TiF}_{4}$ alone. Further studies are required to investigate the optimal etching time for enamel after tooth conditioning with $\mathrm{TiF}_{4}$.

One possible mechanism for the acquired acidresistance by laser-irradiated enamel is via the formation of small empty spaces, which serve as a place for the entrapment and storage of mineral ions released during the acid attack; however, in non-laser irradiated enamel, the ions are released into the surrounding solution. This theory explains enamel resistance to acid following laser irradiation. ${ }^{28}$ Another suggested mechanism is the formation of pyrophosphate following $\mathrm{CO}_{2}$ laser irradiation; the $\mathrm{CO}_{2}$ laser melts and recrystallizes enamel and dentin. ${ }^{12}$ Laser irradiation of enamel causes superficial melting and solubilizes the crystalline structure, followed by recrystallization in the presence of fluoride and formation of fluorapatite, which is less soluble than hydroxyapatite. ${ }^{29}$

Based on the results of the current study, irradiation of the $\mathrm{CO}_{2}$ laser prior to the application of APF has not exhibited an increase in bond strength compared to that of APF alone. It appears that surface recrystallization due to laser irradiation confers resistance to enamel against acid etching and thus decreases bond strength. However, the application of APF results in the deposition of calcium fluoride globules on the tooth surface, which increase surface porosity and enhance the mechanical retention of adhesive and consequently a higher bond strength, ${ }^{30}$ but the durability of this bond in the long term needs to be evaluated in future studies.

In the current study, the $\mu$ SBS of the composite to enamel following the application of APF with/without $\mathrm{CO}_{2}$ laser irradiation was higher than that of TiF4 groups. Contrary to TiF4, APF cannot form an organometallic complex and only forms globular calcium fluoride deposits on the tooth surface, which do not adhere to the surface as strongly as the glaze-like layer formed by TiF4 and cannot perform as a strong barrier against the adequate bond of the composite to the tooth surface. ${ }^{31,32}$

To have a more comprehensive study, TiF4 had to be compared with other fluoridated compounds. Moreover, different laser parameters had to be used, SEM analysis had to be conducted and the procedure had to be carried out over an extended period of time. However, due to some limitations, the study was confined to its present form.

\section{Conclusion}

The application of $\mathrm{TiF}_{4}$ alone and after $\mathrm{CO}_{2}$ laser irradiation on the enamel surface decreased the $\mu \mathrm{SBS}$ of the composite to enamel. APF alone or its use after laser irradiation did not have any adverse effect on the $\mu$ SBS of the composite to enamel.

\section{Ethical Considerations}

Not Applicable.

\section{Conflict of Interests}

The authors declare no conflict of interest.

\section{References}

1. Simón-Soro A, Mira A. Solving the etiology of dental caries. Trends Microbiol. 2015;23(2):76-82. doi: 10.1016/j. tim.2014.10.010.

2. Li X, Wang J, Joiner A, Chang J. The remineralisation of enamel: a review of the literature. J Dent. 2014;42(Suppl 1):S12-S20. doi: 10.1016/S0300-5712(14)50003-6.

3. Wiegand A, Magalhães AC, Navarro RS, Schmidlin PR, Rios D, Buzalaf MAR, et al. Effect of titanium tetrafluoride and amine fluoride treatment combined with carbon dioxide laser irradiation on enamel and dentin erosion. Photomed Laser Surg. 2010;28(2):219-26. doi: 10.1089/ pho.2009.2551.

4. Harris NO, Garcia-Godoi F, Nathe CN. Primary Preventive Dentistry. 7th ed. New Jersey: Pearson Education Inc; 2009.

5. Comar LP, Wiegand A, Moron BM, Rios D, Buzalaf MA, Buchalla W, et al. In situ effect of sodium fluoride or titanium tetrafluoride varnish and solution on carious demineralization of enamel. Eur J Oral Sci. 2012;120(4):342-8. doi: 10.1111/j.1600-0722.2012.00968.x.

6. Charvat J, Söremark R, Li J, Vacek J. Titaniumtetrafluoride for treatment of hypersensitive dentine. Swed Dent J. 1995;19(1-2):41-6.

7. Tveit $\mathrm{AB}$, Hals $\mathrm{E}$, Isrenn $\mathrm{R}$, Tøtdal B. Highly acid $\mathrm{SnF}_{2}$ and $\mathrm{TiF}_{4}$ solutions: Effect on and chemical reaction with root dentin in vitro. Caries Res. 1983;17(5):412-8. doi: 


\section{$10.1159 / 000260695$.}

8. Clark RJH. The Chemistry of Titanium and Vanadium: An Introduction to the Chemistry of the Early Transition Elements. Amsterdam: Elsevier Publishing; 1968.

9. Colucci V, Messias DCF, Serra MC, Corona SAM, Turssi CP. Fluoride plus $\mathrm{CO}_{2}$ laser against the progression of caries in root dentin. Am J Dent. 2012;25(2):114-7.

10. Schmidlin PR, Dörig I, Lussi A, Roos M, Imfeld T. $\mathrm{CO}_{2}$ laser-irradiation through topically applied fluoride increases acid resistance of demineralised human enamel in vitro. Oral Health Prev Dent. 2007;5(3):201-8.

11. Tepper SA, Zehnder M, Pajarola GF, Schmidlin PR. Increased fluoride uptake and acid resistance by $\mathrm{CO}_{2}$ laserirradiation through topically applied fluoride on human enamel in vitro. J Dent. 2004;32(8):635-41. doi: 10.1016/j. jdent.2004.06.010.

12. Rodrigues LKA, dos Santos MN, Pereira D, Assaf AV, Pardi V. Carbon dioxide laser in dental caries prevention. J Dent. 2004;32(7):531-40. doi: 10.1016/j.jdent.2004.04.004

13. Belcheva A, El Feghali R, Nihtianova T, Parker S. Effect of the carbon dioxide 10,600-nm laser and topical fluoride gel application on enamel microstructure and microhardness after acid challenge: an in vitro study. Lasers Med Sci. 2018;33(5):1009-17. doi: 10.1007/s10103-018-2446-4.

14. Molaasadollah F, Asnaashari M, Mashhadi Abbas F, Jafary M. In vitro comparison of fluoride gel alone and in combination with Er,Cr:YSGG laser on reducing white spot lesions in primary teeth. J Lasers Med Sci. 2017;8(4):160165. doi: 10.15171/jlms.2017.29.

15. Meng CL, Li CH, Wang WN. Bond strength with APF applied after acid etching. Am J Orthod Dentofacial Orthop. 1998;114(5):510-3. doi: 10.1016/s0889-5406(98)70170-2.

16. Kimura T, Dunn WJ, Taloumis LJ. Effect of fluoride varnish on the in vitro bond strength of orthodontic brackets using a self-etching primer system. Am J Orthod Dentofacial Orthop. 2004;125(3):351-6. doi: 10.1016/j. ajodo.2003.04.007.

17. Lehmann N, Degrange M. Effect of four dentin desensitizer on the shear bond strength of three bonding systems. Eur Cell Mater. 2005;9(Suppl 1):52-3.

18. Itota T, Torii $Y$, Nakabo S, Yoshiyama M. Effect of fluoride application on tensile bond strength of self-etching adhesive systems to demineralized dentin. J Prosthet Dent. 2002;88(5):503-10. doi: 10.1067/mpr.2002.129079.

19. Ustunkol I, Yazici AR, Gorucu J, Dayangac B. Influence of laser etching on enamel and dentin bond strength of Silorane System Adhesive. Lasers Med Sci. 2015;30(2):695700. doi: 10.1007/s10103-013-1409-z.

20. Azarsina M, Panahandeh N, Gholipour T, Namdari M, Fekrazad R. The effect of titanium tetrafluoride treatment and the $\mathrm{CO}_{2}$ laser on acid resistance of human enamel. J Lasers Med Sci. 2019;10(3):207-10. doi: 10.15171/ jlms.2019.33.

21. Akhavan Zanjani V, Ahmadi H, Nateghifard A, Ghasemi A, Torabzadeh H, Abdoh Tabrizi M, et al. Effect of different laser surface treatment on microshear bond strength between zirconia ceramic and resin cement. J Investig Clin Dent. 2015;6(4):294-300. doi: 10.1111/jicd.12105.

22. Schüpbach P, Lutz F, Finger WJ. Closing of dentinal tubules by Gluma desensitizer. Eur J Oral Sci. 1997;105(5 Pt 1):414-21. doi: 10.1111/j.1600-0722.1997.tb02138.x.

23. Sheykholeslam Z, Buonocore MG, Gwinnett AJ. Effect of fluorides on the bonding of resins to phosphoric acidetched bovine enamel. Arch Oral Biol. 1972;17(7):1037-45. doi: 10.1016/0003-9969(72)90178-1.

24. Wefel JS, Harless JD. The effect of topical fluoride agents on fluoride uptake and surface morphology. J Dental Res. 1981;60(11):1842-8. doi: 10.1177/00220345810600110301.

25. Büyükyilmaz T, Øgaard B, Dahm S. The effect on the tensile bond strength of orthodontic brackets of titanium tetrafluoride $\left(\mathrm{TiF}_{4}\right)$ application after acid etching. $A m$ J Orthod Dentofacial Orthop. 1995;108(3):256-61. doi: 10.1016/s0889-5406(95)70018-8.

26. Skartveit L, Spak CJ, Tveit AB, Selvig KA. Caries-inhibitory effect of titanium tetrafluoride in rats. Acta Odontol Scand. 1991;49(2):85-8. doi: 10.3109/00016359109005891.

27. Mundorff SA, Little MF, Bibby BG. Enamel dissolution: II. Action of titanium tetrafluoride. $J$ Dent Res. 1972;51(6):1567-71. doi: 10.1177/00220345720510061001.

28. Kantola S, Laine E, Tarna T. Laser-induced effects on tooth structure. VI. X-ray diffraction study of dental enamel exposed to a $\mathrm{CO}_{2}$ laser. Acta Odontol Scand. 1973;31(6):369-79. doi: 10.3109/00016357309002524.

29. Rodrigues LKA, Dos Santos MN, Featherstone JDB. In situ mineral loss inhibition by $\mathrm{CO}_{2}$ laser and fluoride. J Dent Res. 2006;85(7):617-21.

30. Chersoni S, Bertacci A, Pashley DH, Tay FR, Montebugnoli $\mathrm{L}$, Prati C. In vivo effects of fluoride on enamel permeability. Clin Oral Investig. 2011;15(4):443-9. doi: 10.1007/s00784010-0406-x.

31. Gwinnett AJ, Buonocore MG, Sheykholeslam Z. Effect of fluoride on etched human and bovine tooth enamel surfaces as demonstrated by scanning electron microscopy. Arch Oral Biol. 1972;17(2):271-8. doi: 10.1016/00039969(72)90210-5.

32. Kochavi D, Gedalia I, Anaise J. Effect of conditioning with fluoride and phosphoric acid on enamel surfaces as evaluated by scanning electron microscopy and fluoride incorporation. J Dent Res. 1975;54(2):304-9. doi: $10.1177 / 00220345750540021901$. 